\title{
Role of Socioeconomic Status (SES) in Globe Injuries: A Review
}

\author{
Panagiotis Kousiouris ${ }^{1} *$ \\ Olga Klavdianou ${ }^{1, *}$ \\ Konstantinos AA Douglas (D) \\ Nikolaos Gouliopoulos (iD) ${ }^{2}$ \\ Klio Chatzistefanou' \\ Maria Kantzanou ${ }^{3}$ \\ Georgios S Dimtsas' \\ Marilita M Moschos' \\ ' Ist Department of Ophthalmology, \\ National and Kapodistrian University of \\ Athens, "G. Gennimatas" General \\ Hospital, Athens, Greece; ${ }^{2} 2$ nd \\ Department of Ophthalmology, National \\ and Kapodistrian University of Athens, \\ "Attikon" General Hospital, Athens, \\ Greece; ${ }^{3}$ Department of Hygiene, \\ Epidemiology and Medical Statistics, \\ Medical School, National and \\ Kapodistrian University of Athens, \\ Athens, Greece \\ *These authors contributed equally to \\ this work
}

Correspondence: Marilita M Moschos Ist Department of Ophthalmology, National and Kapodistrian University of Athens, "G. Gennimatas" General Hospital, Leof. Mesogeion I54, Athens, II 5 27, Greece

Tel +306944887319

Email moschosmarilita@yahoo.fr

\begin{abstract}
Globe injury is a serious worldwide public health issue frequently leading to permanent vision impairment. The plethora of different types of globe injuries is classified into categories, including open and closed globe injuries. Globe injury occurs mainly in the workplace and at home, affecting predominantly middle-aged working men. Socioeconomic status (SES) is defined by income level, educational attainment, and employment status. Low socioeconomic status has been associated with a higher incidence of globe injury and can be utilized to identify at-risk populations. For managing open and closed globe injuries, different strategies are applied and the implementation of adequate globe injury prevention measures is needed for reducing the occurrence of globe injury. The following article aims to provide an overview of globe injury characteristics and their correlation with socioeconomic status and to highlight the significance of considering SES as a variable in globe injury prevention.
\end{abstract}

Keywords: eye injuries, occupational injuries, social class, educational status

\section{Introduction}

Globe injury, defined as a superficial or intraocular injury or wound caused by a mechanical agent resulting in varying degrees of tissue damage to the eye or the adnexa, presents a serious public health issue worldwide. ${ }^{1,2}$ It remains one of the leading causes of acquired visual impairment across all age groups, with patients sustaining globe injuries requiring hospital admission and/or surgical management. ${ }^{3,4}$ Current data estimate that each year 55 million cases of eye injuries occur resulting in 16 million cases of bilateral blindness and 19 million cases of unilateral blindness. ${ }^{5,6}$ It is easily understood that globe injury imposes a serious negative impact on the patient and the health system as a whole, ${ }^{7}$ with consequences varying but not limited to: the psychological, physical, and socioeconomic effects of visual impairment on the patient (limited career opportunities, lifestyle changes, etc.), the cost of medical expenses for the patient and their families and the economic burden of the health system tasked with managing these cases. ${ }^{6}$

However, while ocular injury presents a wide spectrum of location, nature, and cause of injury, ${ }^{8}$ one of its main features is that, contrary to other causes of visual impairment, $90 \%$ of eye injury cases can be prevented. ${ }^{9,10}$ Therefore, to create effective preventing measures, there is a need for a thorough understanding of the epidemiology and potential risk factors of globe injuries. ${ }^{11}$ One of the key risk factors repeatedly reported in several studies concerning globe injuries is socioeconomic status (SES). ${ }^{1,2,10,12-15}$ The incidence of ocular trauma tends to be higher 
in patients of lower SES, meaning of lower education, occupation and income status. By studying the role of socioeconomic status in globe injuries and, therefore, defining which population is truly at risk, the best strategy for the prevention of globe injuries can be achieved.

This review article offers a comprehensive overview of the relation between socioeconomic status and globe injuries and its potential role in creating effective preventive measures.

\section{Classification of Globe Injuries}

Various models have been created by the scientific community to classify ocular trauma and predict the final visual outcome. ${ }^{16-18}$ To standardize the terminology of eye injury and accurately describe eye injuries of all types, various ocular trauma societies use the Birmingham Eye Trauma Terminology (BETT). According to BETT, which uses as the tissue of reference the entire globe, eye injury is divided into open globe injury and closed globe injury. Open globe injury is defined as a "full-thickness wound of the eyewall" and closed globe injury is defined as a "non-full-thickness wound of the eyewall". When referring to the eyewall, for practical purposes, only the sclera and cornea are taken into consideration. Open globe injury is subdivided into rupture meaning "a full-thickness wound of the eyewall by a blunt object"- and in laceration - meaning "a full-thickness wound of the eyewall by a sharp object"- which further entails intraocular foreign bodies, penetrating injury (entrance wound only) and perforation (entrance and exit wounds). Closed globe injury is further divided into lamellar laceration, defined as "a partial-thickness wound of the eyewall", and contusion, meaning "a blow to the eyewall causing partial-thickness wound". ${ }^{19-21}$

The Ocular Trauma Classification Group has created a system based on BETT, to classify mechanical injuries of the eye, excluding chemical, electrical, and thermal ocular injuries. This system categorizes both open and closed eye injuries according to four parameters: type of injury, based on the mechanism that caused the wound, grade of injury, meaning visual acuity at the initial examination, presence or absence of a relative afferent pupillary defect, and zone of injury. ${ }^{17}$

In 2002, Kuhn et al created the Ocular Trauma Score (OTS), which acts as a prognostic tool in open globe injuries for predicting the final visual outcome. The variables necessary to calculate OTS at initial clinical presentation are initial visual acuity, rupture, endophthalmitis, perforating injury, retinal detachment, and afferent pupillary defect. ${ }^{16}$ Another prognostic model for open globe injuries was created by Schmidt et al using the classification and regression tree (CART) analysis. CART is used to predict vision survival or no vision and is commonly used as a guide following treatment. ${ }^{18}$ Since the development of these prognostic models, several studies have assessed their accuracy in predicting the visual outcome, ${ }^{8,22-25}$ with some suggesting modifications to the variables taken into account, ${ }^{26,27}$ in order to include a broader range of ocular injuries, such as adnexal injuries and nonmechanical injuries. ${ }^{28}$ Nevertheless, these models present a useful tool in the hands of the clinician to achieve the fastest assessment of the trauma and the best suitable management decision.

\section{Epidemiology of Globe Injuries}

Several studies have analyzed the epidemiology of globe injuries. ${ }^{1-3,5,6,8,9,11,23,27,29-37}$ In industrialized countries, traumatic eye injuries are the most common cause of visits to the emergency room. ${ }^{37}$ Hospital admission and further treatment are often needed for these type of injuries, whose incidence reportedly ranges from 8.6 to 89 per 100,000 population-years. ${ }^{3}$ Across all studies, some universal characteristics of globe injury can be observed. There is a clear male predominance, with the male to female ratio in some studies reaching a $4: 1$. $^{1-3,6,9,11,23,32}$ This can be attributed to occupational exposure, risktaking activities, and harmful behavior, such as alcohol consumption. ${ }^{23}$ Unilateral globe injuries are more common, ${ }^{5}$ with most patients being in their third decade of life. ${ }^{1-3,9,23,36}$ The most common location where the injury occurred was either the workplace ${ }^{1,3,8,9,11,23,31,32}$ or the home. ${ }^{6,34}$ The most frequently reported mechanisms of injury were: trauma by foreign objects including organic objects, such as particles of sand or wood and metal objects, such as wire, metal bar, nail, hammer, ${ }^{1,6,9,11}$ penetrating injuries by pellets, firecrackers and equipment explosion, shotgun injuries, motor vehicle crashes and domestic accidents like falls. ${ }^{6,11}$

Interestingly enough, when analyzed according to sex, the male prevalence was reported in all mechanisms of injury except domestic falls, where the majority of patients were females. ${ }^{31,36}$ When the mechanism of injury was organized according to age groups, motor vehicle accidents, explosions, and shotgun injuries were more common in younger patients in their early third decade of life, trauma by foreign objects was most common in the middle-aged working population and domestic falls were more 
common in the elderly, possibly due to comorbidities like connective tissue disease, osteoporosis and degenerative neurological diseases. ${ }^{6,9,27,36}$

As far as the type of injury is concerned, there were conflicting results regarding the proportions of open and closed globe injuries, with some studies reporting similar percentages for both, ${ }^{3}$ others reporting more closed globe injuries, ${ }^{1}$ and others reporting a predominance of open globe injuries. ${ }^{6}$ Nevertheless, for open globe injuries, the most common conditions were an intraocular foreign body, corneal penetration, and rupture, ${ }^{3,6,11}$ while for closed globe injuries lamellar lacerations, contusions, traumatic lens subluxation or dislocation, and traumatic corneal ulcer were most frequently observed. ${ }^{1,3,6}$

Factors influencing the final visual outcome in all types of eye injuries included: initial visual acuity, corneal and anterior segment wound, posterior extent and length of the wound, presence of hyphaema or retinal vitreous pathologies, such as vitreous prolapse, optic nerve damage, and others. ${ }^{11,34}$ Injuries classified as Zone III had a poorer prognostic result compared to other zones, ${ }^{31}$ while when injuries were limited to the eyelid or adnexa the final visual outcome was better compared to both open and closed globe injuries. $^{3}$

\section{Overview of Socioeconomic Factors}

Socioeconomic status (SES) has been defined as

a broad concept that refers to the placement of persons, families, households and census tracts or other aggregates with respect to the capacity to create or consume goods that are valued in our society. ${ }^{38}$

Several factors comprise and define socioeconomic status. Traditionally, SES is measured by employment status, educational attainment, and income level. Employment status is further defined as being employed, unemployed, or belonging to a specific occupational group (eg, agricultural workers). Educational attainment is assessed by the continuous years of education completed and the credentials earned (eg, high-school diploma, bachelor's degree, master's degree, Ph.D., etc.). Income level includes the individual's annual income, the annual household income, and/or the family income. ${ }^{38,39}$

In order to categorize SES, several different indexes have been utilized, with the Hollingshead (1975) fourfactor index of SES being one of the most frequently used to accumulate an SES score. The four factors used in the Hollingshead index are: education, occupation, sex, and marital status. Education status receives a 1 through 7 score, with 1 representing a less than a seventh-grade education and 7 being graduate training. Occupation receives a 1 through 9 score, with 1 being equal to farm laborers/menial service workers and 9 being equal to higher executives, proprietors of large businesses and major professionals. Both scores are weighted to compute a single score, ranging from 8 to 66 , which corresponds to five social strata (major business and professional/medium business, minor professional, technical/skilled craftsmen, clerical, sales workers/machine operators, semiskilled workers/unskilled laborers, menial service workers) (Hollingshead AB. Four Factor Index of Social Status; 1975. [Unpublished document, Yale University, New Haven, CT]).

It is well accepted that low socioeconomic status plays a role in an individual's health, morbidity, and mortality. SES impacts an individual's health status through controlling aspects like access to medical facilities, participation in health screening, medical insurance, and more. ${ }^{39}$ Unfortunately, information about an individual's SES is usually not collected, therefore it is often hard to assess the at-risk population through socioeconomic factors. The need to assess these factors is particularly prominent in globe injuries, due to the large role that socioeconomic factors seem to play in globe injuries' epidemiology. Workplace, as it has been aforementioned, is the most common location for eye injuries to occur. ${ }^{11}$ In industrialized countries, the construction and manufacturing industry present the highest incidence of globe injuries, while in countries with mainly agricultural workers there is a higher risk of eye injuries due to environmental exposure, lack of protection, and adverse working conditions. ${ }^{1}$ Socioeconomic factors also have an impact in urban societies influencing high-risk behaviors, such as urban violence, gunshot injuries, motor vehicle crashes, sports practice, etc., which are often responsible for many types of globe injury. ${ }^{41}$

\section{Socioeconomic Status and Globe Injuries}

Through several studies, a trend has been reported for the rising prevalence of globe injuries with rising socioeconomic deprivation. ${ }^{1,2,7,8,10,14,36,41,42}$ Immigrants, ${ }^{5,9}$ ethnic minorities, ${ }^{41}$ non-permanent residents, ${ }^{8}$ and residents of rural areas outside the bigger city centers, ${ }^{1,32}$ all had a higher incidence of globe injuries reported. This could 
be because it has been noted that residents outside city centers choose to seek help only in more serious cases. ${ }^{32}$ However, Low et al reported that lack of geographical access played no role in the incidence of eye injuries and other factors, such as health-seeking behavior, patient anxiety, patient education, etc., should be considered. ${ }^{2}$ Employment status and type of occupation play also a crucial role across most studies in the globe injury occurrence. In both rural and urban areas, ${ }^{5}$ people conducting manual work, such as industry works, factory workers, and construction workers, had a higher prevalence of globe injuries when compared to non-manual workers, liberals, and civil servants. ${ }^{13,43-45}$ Especially high incidence was reported in younger inexperienced manual workers ${ }^{45}$ and more occupational accidents were reported in the years of the economic crisis, possibly due to the unemployment rates resulting in workplace tension, the bigger volume of work, and disregard for safety issues. ${ }^{6}$ Educational attainment seemed to be impacting the occurrence of globe injuries, with studies reporting participants having a lower educational status than the general population, ${ }^{8}$ namely many having completed middle school ${ }^{1,44}$ or high school. ${ }^{14}$ This correlation may be because people with higher educational status are better informed and thus exercise more caution and/or on the other hand, people with lower educational attainment acquire jobs with more exposure to harmful conditions. ${ }^{14}$ Financial status influenced the incidence of eye injuries. Individuals with a lower annual income, ${ }^{14}$ residence in poorer and deprived areas, ${ }^{1}$ no health insurance, ${ }^{14,44}$ or benefiting from financial relief programs, ${ }^{7}$ demonstrated higher rates of eye injuries, probably due to lacking the necessary resources to deal with these type of injuries and also being disproportionately exposed to high-risk conditions. ${ }^{10}$ For people especially living in socioeconomically deprived areas, another factor influencing the prevalence and mechanism of injury was intoxication, leading to higher rates of injuries via assault, ${ }^{2}$ a phenomenon connected to low socioeconomic status by the theory previously described as "social selection or drift". ${ }^{46}$ A similar correlation between SES and ocular trauma has also been described for the pediatric population. ${ }^{47}$ When taken together as a whole, studies outlined that socioeconomic status correlated with the incidence of eye injuries, with people of lower socioeconomic status or people living in socioeconomically deprived areas exhibiting higher percentages of eye injuries. ${ }^{2,41}$

\section{Management of Globe Injuries}

Assessment of ocular and periocular injuries can be an intimidating task and the utmost efficacy and speed are often needed. A thorough medical history is taken to determine age and occupation, the extent and mechanism of injury, a prominent example being chemical injury where the nature of the chemical determines the nature of the treatment, time and place of injury, treatment of the injury before the presentation and previous ocular and medical history. ${ }^{48}$ Furthermore, an ocular examination is performed including inspection for obvious injuries such as contusions and intraocular foreign bodies, assessment of visual acuity and orbital wall, ocular mobility and adnexae integrity, careful exploration of the upper and lower fornix, conjunctiva, cornea, and sclera, and anterior chamber for the presence of lacerations, foreign bodies, hyphaema and more, evaluation of the presence of the relative afferent pupillary defect (RAPD), estimation of the lens and posterior segment morphology and measurement of the intraocular pressure (IOP). ${ }^{49,50}$ Based on the findings, globe injuries are classified as non-globe injuries, mechanical globe injuries, or non-mechanical globe injuries. The mechanical globe injuries are further classified according to the Birmingham Eye Trauma Terminology (BETT) system. ${ }^{17,49}$

The management of open globe injury entails protection of the eye with a plastic/metal shield, CT scan of the brain and orbits and/or gentle b-scan ultrasound to detect and rule out intraocular foreign bodies (IOFBs), administration of systemic antibiotics within 6 hours of injury, tetanus toxoid and if needed antiemetics and analgesics and arrangement for surgical repair. ${ }^{50,51}$ Intravitreal antibiotics are recommended in patients with a high risk of infection, eg, retained IOFBs, rupture of the lens capsule, long delay of surgical repair. ${ }^{50}$ In the case of IOFBs, surgical extraction is considered due to the potential complications of leaving IOFBs in place. The nature of the IOFBs determines the treatment strategy: organic IOFBs degrade over time and are removed due to the high risk of orbital cellulitis, small, deeply stationed metallic objects can be managed conservatively, metals such as iron, copper, and ferromagnetic IOFBs have a risk of severe inflammation and are removed, gunshot pellets are made of 80 $90 \%$ lead and $10-20 \%$ iron and thus are removed. ${ }^{52}$ It is important to note that the timing of surgery plays an essential role in the treatment. Patients of lower SES, due to limited access to healthcare, often have a delay in 
presentation, which can significantly influence the treatment plan and final outcome. ${ }^{53}$

The management of closed globe injury includes contusion, protection of the eye with a plastic/metal shield and in the presence of hyphaema, positioning of the head at 30-45 degrees, cycloplegics for the affected eye, and avoidance of antiplatelet/anticoagulation medications. For lamellar laceration, administration of antibiotic ointment and a pressure patch for the first 24 hours for comfort, for large lacerations ( $\geq 1$ to $1.5 \mathrm{~cm}$ ) suturing may be applied and in the case of dirty wounds, tetanus toxoid may be administrated. ${ }^{50,51}$ If superficial foreign bodies (FBs) are present, a topical anesthetic is applied and the FBs are removed either with a cotton-tipped applicator or with irrigation. The Rust ring left by metallic FBs is removed as completely as possible, the $\mathrm{pH}$ is evaluated if a chemical injury is suspected (eg, alkali from fireworks) and antibiotic ointment is instilled. ${ }^{50}$ For chemical injuries, rapid irrigation of the affected eye with saline or Ringer lactate solution or tap water in the absence of both is necessary. ${ }^{51}$

\section{Prevention of Globe Injuries}

In contrary to the plethora of information about the description and occurrence of globe injuries, relatively less data are available on the aspect of globe injury prevention. ${ }^{54}$ Considering the risk of permanent visual impairment, the need for hospitalization and the burden of globe injuries on the individual and the health system as a whole, globe injury prevention strategies present a clear priority as a public health issue. ${ }^{3}$ Eye protection devices are selected based on the activity that imposes a risk for eye injury. They act as a barrier between the eye and mechanical, thermal, chemical, radioactive, and actinic injury. ${ }^{54}$ As mentioned before, a large number of eye injuries occurred in the workplace. In theory, it is mandatory to use eye protection devices while being in the workplace, especially for highrisk occupations like the construction industry and agriculture. ${ }^{8,55}$ However, several studies reported that the vast majority of individuals sustaining eye injury were not using eye protection ${ }^{1,3,8,32,44,56,57}$ nor were they informed of the dangerous properties they were handling or how to perform first aid in case of an injury. ${ }^{12,58}$ Possible reasons for this behavior may include discomfort from the device, vision limitation, shyness, and lack of proper education. ${ }^{59,60}$

Educational programs raising awareness are required for all workers. By underlining the high risk of permanent vision impairment through an eye injury, attention will be brought to the subject of accurate use of eye protection in the workplace and, in this current digital era, social media could be major contributors to this cause. ${ }^{3}$ Furthermore, additional measures should be taken according to the mechanism of injury. In construction, industrial industry, and agriculture, face masks and shields could be implemented to protect the eye and the adnexae from mechanical injuries. In agriculture, sunglasses may be needed for protection from excessive sun exposure. Visual ergonomic measures, such as blue light filters, are proposed for those working in the technological industry. ${ }^{61}$ As far as sport-related eye injuries are concerned, sports are classified as low, high, and very high risk. ${ }^{62}$ In the high and very high-risk sports, such as racquet sports, hockey, lacrosse, baseball, basketball, and watersports, facial protection cages and polycarbonate eye and facial protectors are available. ${ }^{21,62}$ Prohibiting firecrackers, ${ }^{63}$ implementing seatbelts and airbags, and educating about traffic regulations and guidelines, ${ }^{22}$ have been noted to reduce the incidence of firework-related and motor vehicle crash-related eye injury, respectively. Fall prevention strategy should also be implemented and specifically to the population at risk, ie, women and the elderly. ${ }^{27}$ It must not be forgotten that since the prevalence and characteristics of ocular injuries are variable, preventive strategies need to be designed based on the special characteristics of each population.

\section{Conclusions}

Globe injury is a serious global public health issue resulting frequently in permanent vision impairment. It is classified into various categories including open and closed globe injuries. Its incidence is higher in the workplace and at home, with the population mainly affected by it being middle-aged men. Many mechanisms of injury have been identified including but not limited to: foreign objects, motor vehicle crashes, and domestic accidents like falls. Socioeconomic status defined by income level, educational attainment, and employment status has been found to negatively correlate with the occurrence of globe injuries and can be used to identify the at-risk population. SES has a great impact on ocular trauma incidence, characteristics and treatment. Preventive strategies have to consider SES as an important variable in future planning. Implementing eye protection strategies can prevent globe injuries and reduce their occurrence in the future. The reduction of such cases is a given that will affect the costs of their treatment. Beneficiaries will be the patients themselves, the health units, and hospitals which will reduce the 
costs of dealing with such situations, the insurance companies, and organizations, and, consequently, the National Health System itself.

\section{Disclosure}

The authors report no conflicts of interest in this work.

\section{References}

1. D'Antone VA, Cely Quiroz L, Palencia Florez DC. Clinical profile of ocular injuries in a geographically isolated Colombian municipality. Int Emerg Nurs. 2020;52:100909. doi:10.1016/j.ienj.2020.100909

2. Low L, Hodson J, Morris D, Desai P, MacEwen C. Socioeconomic deprivation and serious ocular trauma in Scotland: a national prospective study. Br J Ophthalmol. 2017;101(10):1395-1398. doi:10. 1136/bjophthalmol-2016-309875

3. Choovuthayakorn J, Worakriangkrai V, Patikulsila D, et al. Epidemiology of eye injuries resulting in hospitalization, a referral hospital-based study. Clin Ophthalmol. 2020;14:1-6. doi:10.2147/ OPTH.S234035

4. Iftikhar M, Latif A, Farid UZ, Usmani B, Canner JK, Shah SMA. Changes in the incidence of eye trauma hospitalizations in the United States from 2001 through 2014. JAMA Ophthalmol. 2019;137 (1):48-56. doi:10.1001/jamaophthalmol.2018.4685

5. Chua D, Wong W, Lamoureux EL, Aung T, Saw SM, Wong TY. The prevalence and risk factors of ocular trauma: the Singapore Indian eye study. Ophthalmic Epidemiol. 2011;18(6):281-287. doi:10.3109/ 09286586.2011.628775

6. Marta A, Silva N, Correia N, et al. A 15-year retrospective epidemiologic study of ocular trauma in the north of Portugal. Eur J Ophthalmol. 2020:1120672120934399. doi:10.1177/1120672120934399

7. Chen G, Sinclair SA, Smith GA, Ranbom L, Xiang H. Hospitalized ocular injuries among persons with low socioeconomic status: a medicaid enrollees-based study. Ophthalmic Epidemiol. 2006;13 (3):199-207. doi:10.1080/09286580500477440

8. Ji YR, Zhu DQ, Zhou HF, Fan XQ. Epidemiologic characteristics and outcomes of open globe injury in Shanghai. Int $J$ Ophthalmol. 2017;10(8):1295-1300. doi:10.18240/ijo.2017.08.18

9. Larque-Daza AB, Peralta-Calvo J, Lopez-Andrade J. Epidemiology of open-globe trauma in the southeast of Spain. Eur J Ophthalmol. 2010;20(3):578-583. doi:10.1177/112067211002000307

10. Mir TA, Canner JK, Zafar S, Srikumaran D, Friedman DS, Woreta FA. Characteristics of open globe injuries in the United States from 2006 to 2014. JAMA Ophthalmol. 2020;138 (3):268-275. doi:10.1001/jamaophthalmol.2019.5823

11. Batur M, Seven E, Esmer O, Akaltun MN, Yasar T, Cinal A. Epidemiology of adult open globe injury. J Craniofac Surg. 2016;27(7):1636-1641. doi:10.1097/SCS.0000000000003001

12. Chang CH, Chen CL, Ho CK, Lai YH, Hu RC, Yen YL. Hospitalized eye injury in a large industrial city of South-Eastern Asia. Graefes Arch Clin Exp Ophthalmol. 2008;246(2):223-228. doi:10.1007/ s00417-007-0733-z

13. Lee JS, Chen WM, Huang LH, et al. Epidemiology of outpatient and inpatient eye injury in Taiwan: 2000, 2005, 2010, and 2015. PLoS One. 2020;15(7):e0235208. doi:10.1371/journal.pone.0235208

14. Luo H, Beckles GL, Fang X, Crews JE, Saaddine JB, Zhang X. Socioeconomic status and lifetime risk for workplace eye injury reported by a us population aged 50 years and over. Ophthalmic Epidemiol. 2012;19(2):103-110. doi:10.3109/09286586.2011.639977

15. Zvorničanin J, Zvorničanin E. Socioeconomic status and decreasing incidence of ocular injuries in Bosnia and Herzegovina. Semin Ophthalmol. 2021;36(7):517-522. doi:10.1080/08820538.2021.1893350
16. Kuhn F, Maisiak R, Mann L, Mester V, Morris R, Witherspoon CD. The Ocular Trauma Score (OTS). Ophthalmol Clin North Am. 2002;15(2):163-5, vi. doi:10.1016/S0896-1549(02)00007-X

17. Pieramici DJ, Sternberg P Jr, Aaberg TM Sr, et al. A system for classifying mechanical injuries of the eye (globe). The Ocular Trauma Classification Group. Am J Ophthalmol. 1997;123 (6):820-831. doi:10.1016/S0002-9394(14)71132-8

18. Schmidt GW, Broman AT, Hindman HB, Grant MP. Vision survival after open globe injury predicted by classification and regression tree analysis. Ophthalmology. 2008;115(1):202-209. doi:10.1016/j. ophtha.2007.04.008

19. Kuhn F, Morris R, Witherspoon CD. Birmingham Eye Trauma Terminology (BETT): terminology and classification of mechanical eye injuries. Ophthalmol Clin North Am. 2002;15(2):139-43, v. doi:10.1016/S0896-1549(02)00004-4

20. Kuhn F, Pieramici DJ. Ocular Trauma: Principles and Practice. Thieme; 2002.

21. Micieli JA, Easterbrook M. Eye and orbital injuries in sports. Clin Sports Med. 2017;36(2):299-314. doi:10.1016/j.csm.2016.11.006

22. Gupta R, Gupta S, Chauhan L. Predicting visual outcome after open globe injury using classification and regression tree model: the Moradabad ocular trauma study. Can J Ophthalmol. 2019;54 (4):473-478. doi:10.1016/j.jcjo.2018.08.004

23. Kim JH, Yang SJ, Kim DS, Kim JG, Yoon YH. Fourteen-year review of open globe injuries in an urban Korean population. J Trauma. 2007;62(3):746-749. doi:10.1097/01.ta.0000231557.58471.e3

24. Rao LG, Ninan A, Rao KA. Descriptive study on ocular survival, visual outcome and prognostic factors in open globe injuries. Indian J Ophthalmol. 2010;58(4):321-323. doi:10.4103/0301-4738.64116

25. Unver YB, Kapran Z, Acar N, Altan T. Ocular trauma score in open-globe injuries. J Trauma. 2009;66(4):1030-1032. doi:10.1097/ TA.0b013e 3181883d 83

26. Agrawal R, Shah M, Mireskandari K, Yong GK. Controversies in ocular trauma classification and management: review. Int Ophthalmol. 2013;33 (4):435-445. doi:10.1007/s10792-012-9698-y

27. Beshay N, Keay L, Dunn H, Kamalden TA, Hoskin AK, Watson SL. The epidemiology of open globe injuries presenting to a tertiary referral eye hospital in Australia. Injury. 2017;48(7):1348-1354. doi:10.1016/j.injury.2017.04.035

28. Shukla B, Agrawal R, Shukla D, Seen S. Systematic analysis of ocular trauma by a new proposed ocular trauma classification. Indian J Ophthalmol. 2017;65(8):719-722. doi:10.4103/ijo.IJO_241_17

29. Casson RJ, Walker JC, Newland HS. Four-year review of open eye injuries at the Royal Adelaide Hospital. Clin Exp Ophthalmol. 2002;30(1):15-18. doi:10.1046/j.1442-9071.2002.00484.x

30. Falcão M, Camisa E, Falcão-Reis F. Characteristics of open-globe injuries in northwestern Portugal. Ophthalmologica. 2010;224 (6):389-394. doi:10.1159/000316689

31. Fujikawa A, Mohamed YH, Kinoshita H, et al. Visual outcomes and prognostic factors in open-globe injuries. BMC Ophthalmol. 2018;18 (1):138. doi:10.1186/s12886-018-0804-4

32. Jafari AK, Anvari F, Ameri A, Bozorgui S, Shahverdi N. Epidemiology and sociodemographic aspects of ocular traumatic injuries in Iran. Int Ophthalmol. 2010;30(6):691-696. doi:10.1007/ s10792-010-9401-0

33. Knyazer B, Bilenko N, Levy J, et al. Open globe eye injury characteristics and prognostic factors in southern Israel: a retrospective epidemiologic review of 10 years experience. Isr Med Assoc J. 2013;15(3):158-162.

34. Madhusudhan AP, Evelyn-Tai LM, Zamri N, Adil H, Wan-Hazabbah WH. Open globe injury in Hospital Universiti Sains Malaysia - A 10-year review. Int J Ophthalmol. 2014;7(3):486-490. doi:10.3980/j. issn.2222-3959.2014.03.18

35. Mansouri M, Faghihi H, Hajizadeh F, et al. Epidemiology of open-globe injuries in Iran: analysis of 2340 cases in 5 years (report no. 1). Retina. 2009;29(8):1141-1149. doi:10.1097/IAE.0b013e3181a395ac 
36. Okamoto Y, Morikawa S, Okamoto F, et al. Clinical characteristics and outcomes of open globe injuries in Japan. Jpn J Ophthalmol. 2019;63(1):109-118. doi:10.1007/s10384-018-0638-x

37. Samoilă O, Ostriceanu S, Samoilă L. Epidemiology of ocular emergencies in Cluj ophthalmology clinic. Rom J Ophthalmol. 2016;60 (3):165-169.

38. Shavers VL. Measurement of socioeconomic status in health disparities research. J Natl Med Assoc. 2007;99(9):1013-1023.

39. Chan CQH, Lee KH, Low LL. A systematic review of health status, health seeking behaviour and healthcare utilisation of low socioeconomic status populations in urban Singapore. Int $J$ Equity Health 2018;17(1):39. doi:10.1186/s12939-018-0751-y

40. Négrel AD, Thylefors B. The global impact of eye injuries. Ophthalmic Epidemiol. 1998;5(3):143-169. doi:10.1076/opep.5.3. 143.8364

41. Corfield AR, MacKay DF, Pell JP. Association between trauma and socioeconomic deprivation: a registry-based, Scotland-wide retrospective cohort study of 9238 patients. Scand J Trauma Resusc Emerg Med. 2016;24:90. doi:10.1186/s13049-016-0275-7

42. Nirmalan PK, Katz J, Tielsch JM, et al. Ocular trauma in a rural south Indian population: the Aravind Comprehensive Eye Survey. Ophthalmology. 2004;111(9):1778-1781. doi:10.1016/j.ophtha.2004. 02.012

43. Le Q, Chen Y, Wang X, Hong J, Sun X, Xu J. Analysis of medical expenditure and socio-economic status in patients with ocular chemical burns in East China: a retrospective study. BMC Public Health. 2012;12:409. doi:10.1186/1471-2458-12-409

44. Martin-Prieto S, Álvarez-peregrina C, Thuissard-Vasallo I, et al. Description of the epidemiological characteristics of work-related eye injuries in Spain: a retrospective study. BMJ Open. 2020;10 (10):e035696. doi:10.1136/bmjopen-2019-035696

45. Erskine S, Maheswaran R, Pearson T, Gleeson D. Socioeconomic deprivation, urban-rural location and alcohol-related mortality in England and Wales. BMC Public Health. 2010;10:99. doi:10.1186/ 1471-2458-10-99

46. Singh S, Sharma B, Kumar K, Dubey A, Ahirwar K. Epidemiology, clinical profile and factors, predicting final visual outcome of pediatric ocular trauma in a tertiary eye care center of Central India. Indian J Ophthalmol. 2017;65(11):1192-1197. doi:10.4103/ijo.IJO 37517

47. Pargament JM, Armenia J, Nerad JA. Physical and chemical injuries to eyes and eyelids. Clin Dermatol. 2015;33(2):234-237. doi:10. 1016/j.clindermatol.2014.10.015

48. Mutie D, Mwangi N. Assessing an eye injury patient. Community Eye Health. 2015;28(91):46-48.

49. Bagheri N, Wajda B, Calvo C, Durrani A. The Wills Eye Manual: Office and Emergency Room Diagnosis and Treatment of Eye Disease. Wolters Kluwer Health; 2016.
50. Mutie D, Mwangi N. Managing eye injuries. Community Eye Health. 2015;28(91):48-49.

51. Dolar Bilge A, Yılmaz H, Yazıcı B, Naqadan F. Intraorbital foreign bodies: clinical features and outcomes of surgical removal. Ulus Travma Acil Cerrahi Derg. 2016;22(5):432-436. doi:10.5505/tjtes. 2016.20925

52. Jovanovic N, Peek-Asa C, Swanton A, et al. Prevalence and risk factors associated with work-related eye injuries in Bosnia and Herzegovina. Int J Occup Environ Health. 2016;22(4):325-332.

53. Hoskin AK, Mackey DA, Keay L, Agrawal R, Watson S. Eye injuries across history and the evolution of eye protection. Acta Ophthalmol. 2019;97(6):637-643.

54. Limbu B, Moore G, Marvasti AH, Poole ME, Saiju R. Work related ocular injury: Nepal. Nepal J Ophthalmol. 2018;10(19):47-56. doi:10.3126/nepjoph.v10i1.21689

55. Yu TS, Liu H, Hui K. A case-control study of eye injuries in the workplace in Hong Kong. Ophthalmology. 2004;111(1):70-74. doi:10.1016/j.ophtha.2003.05.018

56. Serinken M, Turkcuer I, Cetin EN, Yilmaz A, Elicabuk H, Karcioglu O. Causes and characteristics of work-related eye injuries in western Turkey. Indian J Ophthalmol. 2013;61(9):497-501. doi:10.4103/0301-4738.119435

57. Hong J, Qiu T, Wei A, Sun X, Xu J. Clinical characteristics and visual outcome of severe ocular chemical injuries in Shanghai. Ophthalmology. 2010;117(12):2268-2272. doi:10.1016/j.ophtha.2010.03.050

58. Chatterjee S, Agrawal D. Primary prevention of ocular injury in agricultural workers with safety eyewear. Indian J Ophthalmol. 2017;65(9):859-864. doi:10.4103/ijo.IJO_334_17

59. Monaghan PF, Bryant CA, McDermott RJ, Forst LS, Luque JS, Contreras RB. Adoption of safety eyewear among citrus harvesters in rural Florida. J Immigr Minor Health. 2012;14(3):460-466. doi:10.1007/s10903-011-9484-3

60. Martín-Prieto S, Álvarez-peregrina C, Thuissard-Vassallo I, et al. Eye injuries epidemiology description in a working population over 10 years in Spain. Int J Environ Res Public Health. 2020;17 (12):4454.

61. Rodriguez JO, Lavina AM, Agarwal A. Prevention and treatment of common eye injuries in sports. Am Fam Physician. 2003;67 (7):1481-1488.

62. Wisse RP, Bijlsma WR, Stilma JS. Ocular firework trauma: a systematic review on incidence, severity, outcome and prevention. Br J Ophthalmol. 2010;94(12):1586-1591. doi:10.1136/bjo.2009.168419

63. Pearlman JA, Au Eong KG, Kuhn F, Pieramici DJ. Airbags and eye injuries: epidemiology, spectrum of injury, and analysis of risk factors. Surv Ophthalmol. 2001;46(3):234-242. doi:10.1016/S00396257(01)00256-9
Clinical Ophthalmology

\section{Publish your work in this journal}

Clinical Ophthalmology is an international, peer-reviewed journal covering all subspecialties within ophthalmology. Key topics include: Optometry; Visual science; Pharmacology and drug therapy in eye diseases; Basic Sciences; Primary and Secondary eye care; Patient Safety and Quality of Care Improvements. This journal is indexed on PubMed
Dovepress

Central and CAS, and is the official journal of The Society of Clinical Ophthalmology (SCO). The manuscript management system is completely online and includes a very quick and fair peer-review system, which is all easy to use. Visit http://www.dovepress.com/ testimonials.php to read real quotes from published authors. 